\title{
On the structural changes in the nickel-base alloy EI893 during operation
}

\author{
Y.P. Tarasenko ${ }^{\dagger}$, O. B. Berdnik, S. V. Kirikov, V. N. Perevezentsev \\ †npktribonika@yandex.ru
}

Institute of problems of mechanical engineering, RAS, 85 Belinsky st., 03024, Nizhny Novgorod, Russia

A comparative qualitative and quantitative analysis of the microstructure and phase composition of the alloy EI893 (KhN65VMTYu) was performed, on the example of turbine rotor blades with different operating times. The characteristic changes in the parameters of strengthening phases were revealed, which allows to judge about the degree of degradation of the material structure during operation and the possibility of extending the life of the products with timely repairs.

Keywords: rotor blades, nickel-base alloy, microstructure, intermetallic phase, carbides, heat treatment.

\section{Introduction}

Rotor blades are important elements of gas-turbine engines (GTE). They operate under complex loading conditions, in the conditions of gas corrosion at temperatures of 580 $800^{\circ} \mathrm{C}$, which has an effect on the material structure. The task of extending the operating life of the products and predicting their lifetime cannot be solved without evaluation of the microstructural state at various stages of the alloy's ageing.

To produce turbine blades, wrought and casting nickelbase superalloys (NBSAs) are widely used. The most common NBSAs represent an $f c c$-matrix with the carbide and intermetallic strengthening phases. The high temperature strength of an alloy is in direct relationship with the content of these phases and, consequently, at certain stages of operation their qualitative and quantitative assessment is required.

It is known from literature [1-2] that the service properties of NBSAs are significantly influenced by the homogeneity degree of their grain structure. The presence of variations in grain sizes leads to a reduction in the lifetime of the material of GTE blades. The size and concentration of the strengthening phase particles play an equally important role $[3-4]$.

As a consequence, an analysis of the structure and the phase composition can yield important information about the changes in the state of the material of turbine blades in the process of operation.

\section{Experimental procedure}

The objects of study are second-stage flat rotor blades of a GTE-35-770-2 unit, made of the wrought nickel-base superalloy EI893 (KhN65VMTYu). The following items were selected for analysis:

- a new blade with an operating time of 0 hours;

- a blade after operation with an operating time of
60142 hours;

- a blade after operation with an operating time of 60142 hours and a subsequent regenerative heat treatment (RHT) (quenching + ageing);

- a fractured, due to a long-term overheating, blade with an operating time of 10000 hours.

The samples for microstructure analysis were cut out from the most highly-loaded trailing edges of the blade feather parts.

The microstructural study was conducted on a TESCAN VEGA electron microscope after their etching with Marble's reagent.

\section{Results}

The nickel-base superalloy EI893 (KhN65VMTYu) is hardened by the dispersed particles of the carbide and intermetallic $\mathrm{Ni}_{3}(\mathrm{Al}, \mathrm{Ti})\left(\gamma^{\prime}-\right.$ phase $)$ phases. The percentage of intermetallics varies from 9 to $16 \%$, the fraction of carbides is $\sim 3 \%$. The chemical composition of the alloy is governed by GOST 5632-72.

Investigation of the microstructure of the samples, cut out from the feather part of the blades, allowed to build the histograms of grain size distribution and establish the effect of operation conditions on the grain sizes. Fig. 1 (a,b,c,d) displays the typical histograms of grain size distribution for various conditions of the blades.

The average grain size of the new blade is $d \approx 134 \pm 25 \mu \mathrm{m}$ (Fig.1a).

During operation $\mathrm{d}_{\mathrm{av}}$ changes rather slowly, and after operation for 60142 hours the relative increase in the average grain size is $20 \%$. The spread between the minimum grain size of $50 \mu \mathrm{m}$ and the maximum grain size of $410 \mu \mathrm{m}$ grows, which indicates a growing variation in grain sizes in the structure (Fig.1b).

The use of RHT reduced the spread of the grainsizes: the 
minimum size is $60 \mu \mathrm{m}$, the maximum size is $310 \mu \mathrm{m}$. The distribution maximum is observed at a grain size of $120 \mu \mathrm{m}$ (Fig.1c).

The overheating of the blade in the process of operation led to a considerable grain structure refinement; the largest number of grains have a size of about $50 \mu \mathrm{m}$ (Fig.1d).

Thus, a long-term operation of blades (up to $\sim 60000$ hours) in the range of acceptable operating temperatures does not lead to a considerable change in the grain sizes of the alloy EI893. A long-term overheating in the process of operation led to a decrease in the average grain size.

When analyzing the carbide phase, the carbides in the grain body and the carbides along grain boundaries should be considered separately. Such a division is conditioned by their different influence on the mechanical properties and the specifics of their formation mechanisms.

According to [8], the size of carbides for the alloy EI893 should not exceed $5 \mu \mathrm{m}$. It can be seen from Table 1 that the coagulation of carbides in the grain body proceeds slowly, and if the operation conditions are observed, it does not exceed the acceptable values during the whole lifetime. When the operating temperatures are significantly increased, the speed of this process grows rapidly, thus increasing the probability of the emergence of microcracks at the stress raiser, with the coagulated carbide phase acting as such.

Figure 2 presents photographs of the microstructure of the alloy EI893 in various conditions. In the initial condition there are small carbides observed along grain boundaries (Fig.2a). After operation for 60142 hours, due to the processes of coagulation and additional precipitation, their quantity and size increased (Fig.3b). In the course of high-temperature heat treatment the carbides transform into solid solution and precipitate intensively during ageing, predominantly at grain boundaries (Fig.3c). When the material is overheated (in an emergency situation), the coagulation of the carbide phase takes place predominantly in the grain body, and the additional precipitation takes place at grain boundaries (Fig.3d).

Thus, owing to a partial restoration of the alloy's structure, namely a decrease in the size of the carbide phase precipitates along grain boundaries, a timely heat treatment can extend the life of the product.

A comparative evaluation of the characteristics of the intermetallic phase was conducted for the rotor blades made of the alloy EI893 in various conditions (Table 2).

On basis of the data from table 2, histograms were built, displaying the distribution of the basic characteristics of the $\gamma^{\prime}$ - phase in the nickel-base alloy EI893 depending on the alloy's condition (Fig.3). The following conclusions can be made from the histograms:

- In the process of operation of rotor blades, the average size of the $\gamma^{\prime}$ - phase precipitates of the alloy EI893 grows, while their concentration decreases, the reason for this being the coagulation of the strengthening particles. All this leads to degradation of the strengthening properties of the $\gamma^{\prime}-$ phase.

- A timely regenerative heat treatment partially normalizes the state of the intermetallic phase: reduces the particle sizes 1.3-fold and increases their surface concentration 2-fold.
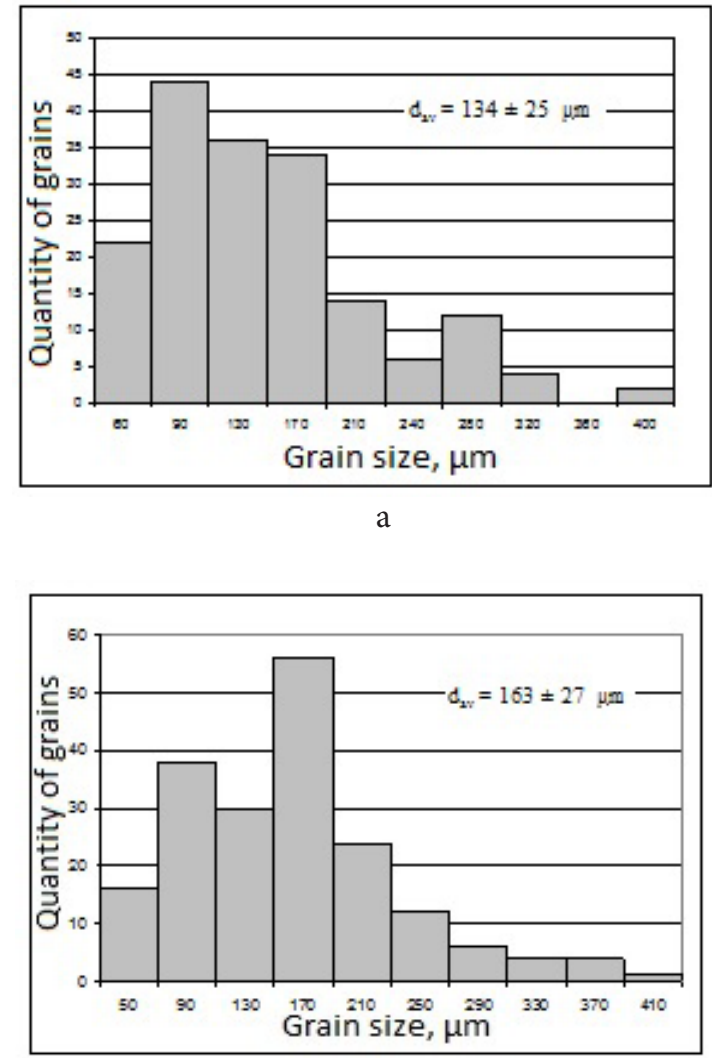

$\mathrm{b}$
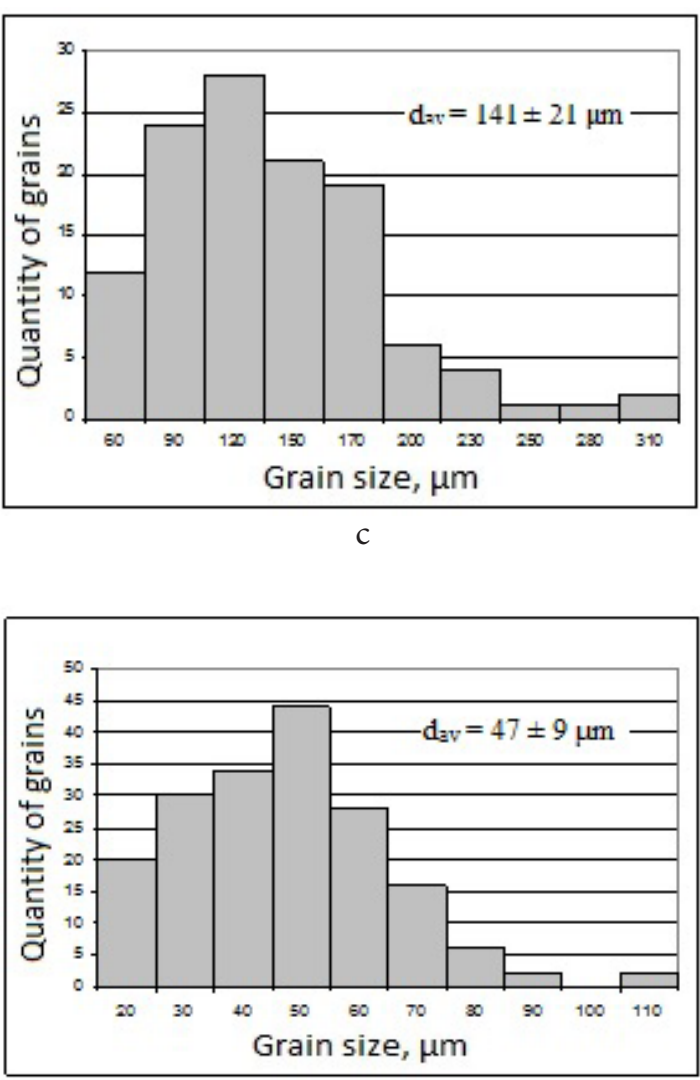

d

Fig. 1. Histograms of the grain size distribution for the alloy EI893, using as an example the samples cut out from the edge of the feather part of rotor blades: (a) a new blade (operating time - 0 h.); (b) operating time 60142 h.; (c) operating time $60142 \mathrm{~h}+$ RHT; (d) (fractured) operating time $10000 \mathrm{~h}$. 

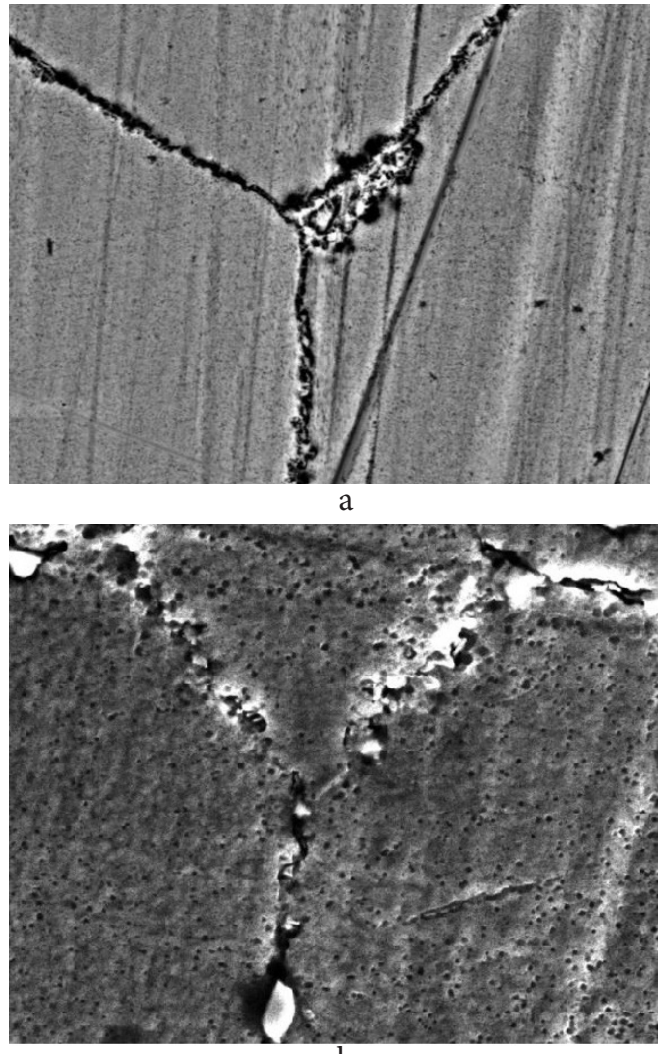

b

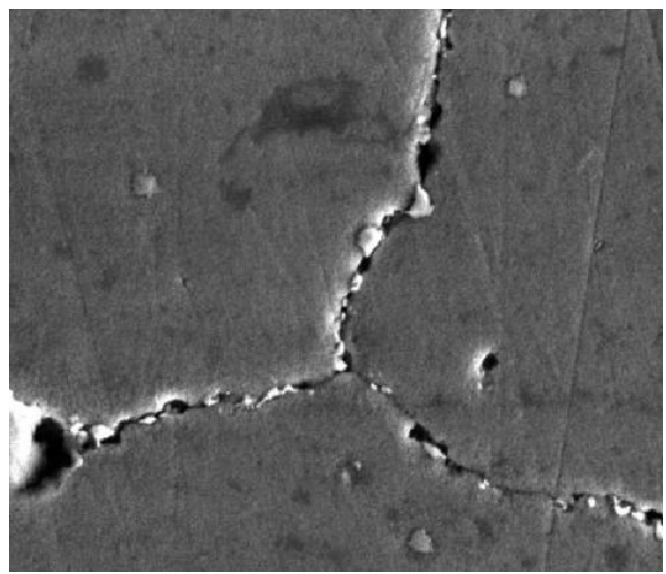

C

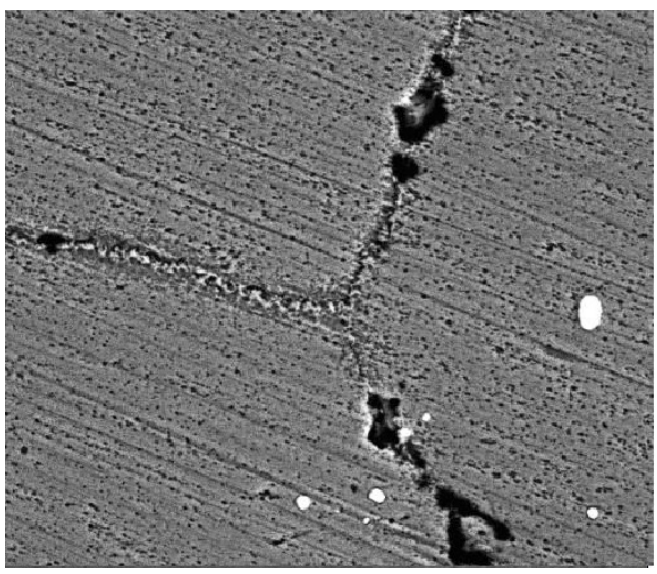

d

Fig. 2. Microstructure of the grain boundaries of the alloy EI983: (a) a new blade (operating time 0 h.); (b) operating time $60142 \mathrm{~h}$.; (c) operating time $60142 \mathrm{~h}$. + RHT; (d) fractured blade (operating time 10000 h.); (x5000).
- In the case of the alloy's overheating, not only a rapid coarsening of the intermetallic phase particles (the average size being $0.34 \mu \mathrm{m}$ ) takes place, but also a transformation of the particles' shape from globular to diamond.

The larger the volume fraction of the strengthening phase and the smaller the particle size, the stronger is the alloy and the higher is its high-temperature strength [3,7].

\section{Conclusions}

It has been shown that if the operation conditions of rotor blades made of the alloy EI893 are observed, the grain
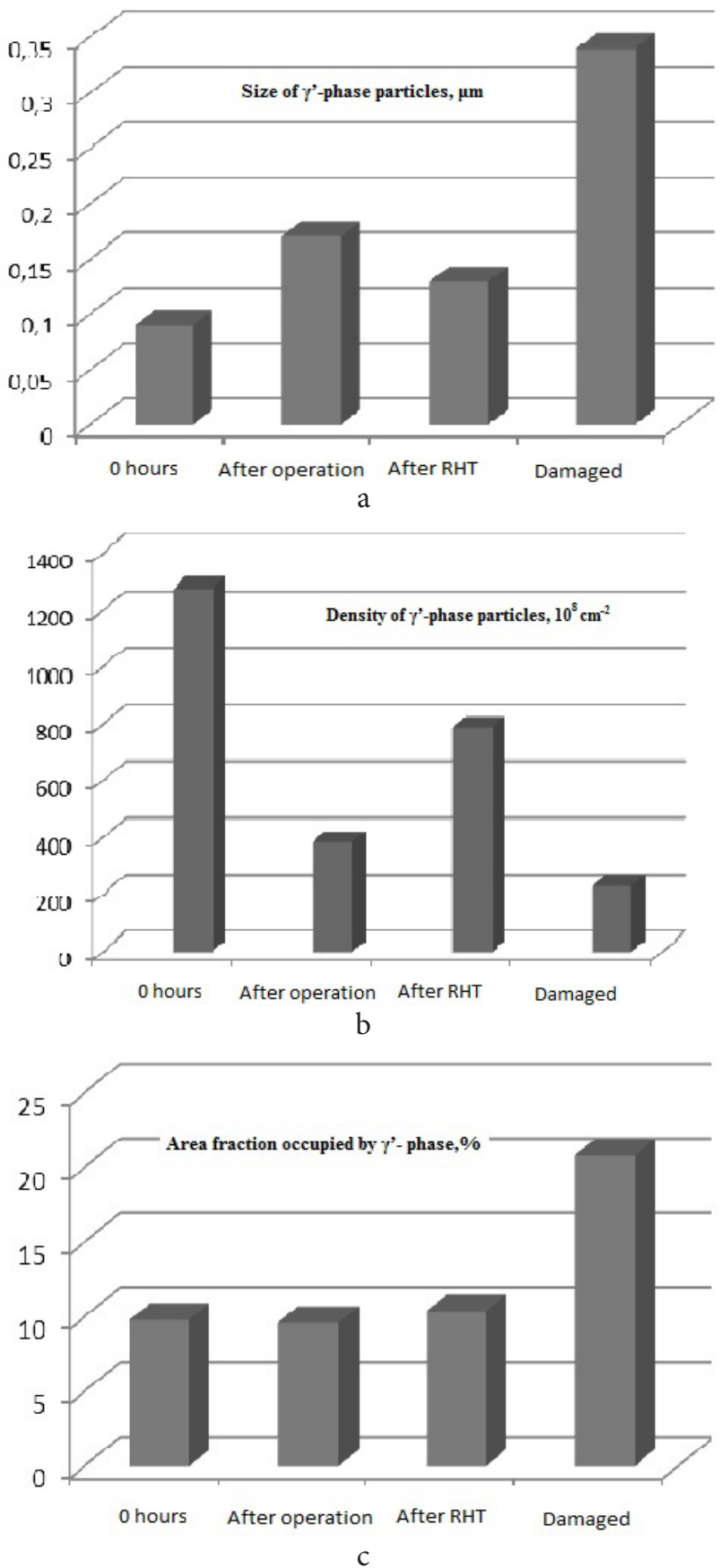

Fig. 3. Histograms showing the distribution of: (a) sizes of the $\gamma^{\prime}$-phase particles; (b) density of the $\gamma^{\prime}$-phase particles; (c) area fraction occupied by the $\gamma^{\prime}$-phase, for various condition of the alloy EI893. 
Table 1.

The carbides size in the alloy EI893 used in turbine blades

\begin{tabular}{|c|c|c|c|c|}
\hline $\begin{array}{c}\text { Material condition } \\
\text { (operating time) }\end{array}$ & $\begin{array}{c}\text { Average size of carbides } \\
\text { in the grain body, } \mu \mathrm{m}\end{array}$ & $\begin{array}{c}\text { Range of sizes, } \\
\mu \mathrm{m}\end{array}$ & $\begin{array}{c}\text { Average size of carbides } \\
\text { along grain boundaries, } \mu \mathrm{m}\end{array}$ & $\begin{array}{c}\text { Linear density of } \\
\text { particles, } 10^{3} \mathrm{~cm}^{-1}\end{array}$ \\
\hline A new blade (0 hours) & 1.7 & $1.1-2.5$ & 0.6 & 5.5 \\
\hline $\begin{array}{c}\text { After operation } \\
(60142 \text { hours) }\end{array}$ & 2.9 & $1.1-4.7$ & 0.85 & 9.5 \\
\hline $\begin{array}{c}\text { After operation } \\
(60142 \text { hours)+RHT }\end{array}$ & 2.0 & $0.9-3.1$ & 0.62 & 9.0 \\
\hline $\begin{array}{c}\text { A fractured blade } \\
(10000 \text { hours })\end{array}$ & 7.6 & $3.4-11.8$ & 0.32 & 16.0 \\
\hline
\end{tabular}

Table 2.

Characteristics of the intermetallic phase of the alloy EI983

\begin{tabular}{|c|c|c|c|}
\hline $\begin{array}{c}\text { Material condition } \\
\text { (operating time) }\end{array}$ & $\begin{array}{c}\text { Size of } \gamma^{\prime} \text {-phase particles, } \\
\mu \mathrm{m} \text {, (shape) }\end{array}$ & $\begin{array}{c}\text { Density of } \gamma^{\prime} \text {-phase } \\
\text { particles, } 10^{8} \mathrm{~cm}^{-2}\end{array}$ & $\begin{array}{c}\text { Area fraction occupied by } \\
\gamma^{\prime} \text {-phase, \% }\end{array}$ \\
\hline A new blade $(0$ hours) & 0.09 (globular) & 12.8 & 9.8 \\
\hline $\begin{array}{c}\text { After operation } \\
(60142 \text { hours) }\end{array}$ & 0.17 (globular) & 3.9 & 10.4 \\
\hline $\begin{array}{c}\text { After operation } \\
(60142 \text { hours) +RHT }\end{array}$ & 0.13 (globular) & 7.9 & 20.8 \\
\hline $\begin{array}{c}\text { Fractured blade } \\
(10000 \text { hours) }\end{array}$ & 0.34 (diamond-shaped) & 2.3 & 9.6 \\
\hline
\end{tabular}

structure and the carbide phase located in the grain body change insignificantly and require only a visual inspection.

The performed comparative analysis of the precipitates of the intermetallic and carbide phases along grain boundaries has shown that during operation structure degradation takes place, manifesting itself in the coagulation, dissolution and additional precipitation of secondary strengthening phases along grain boundaries.

A timely heat treatment partially restores the microstructure, an ordering of the strengthening phases occurs.

In case the temperature regimes of operation are not observed (significant overheating), the following is observed in the alloy structure: an a decrease in the average grain size, an increase in the carbide phase sizes, the coalescence of intermetallic inclusions that precipitated earlier, which reduces the lifetime of the material.

\section{References}

1. L. B. Getsov. Materials and durability of gas turbines. Rybinsk: Gazoturbinnye tehnologii. (2010) 601p. (in Russian)
2. N.V. Dashunin. Forecasting and extension of service life, increasing the reliability of metal in managing the life of stationary gas turbine blading on gas pipelines. Extended abstract of a candidate's thesis. SPb. (2006). 21p. (in Russian)

3. Ch. Sims, W. Hagel. Superalloys. (1976). 567p. (in Russian)

4. S. A. Ivanov. Fatigue resistance of the rotor blades of stationary gas turbines in the scope of life extension. Extended abstract of a candidate's thesis. SPb. (2007). 21p. (in Russian)

5. O.Yu. Ginergart. Influence of grain size on properties of heat-resistant alloys. Conf.: The dynamics of systems, mechanisms and machines. Omsk. (2009) 338-342p. (in Russian)

6. Y.P. Tarasenko, I.N. Tsareva, O. B. Berdnik. Automatic welding. 9, 18 (2011). (in Russian)

7. O. B. Berdnik, I. N. Tsarev, E. N. Razov. Vestnik of Samara State Aerospace University. 3, 240 (2011). (in Russian)

8. SO153-34.17.448-2003 Instructions for extending the lifetime of metal in the core elements of turbines and compressors in power-generating gas turbines. (in Russian) 